\title{
Immunological markers and Helicobacter pylori in patients with stomach cancer: Expression and correlation
}

\author{
JESÚS GUILLERMO ESPINOZA-CONTRERAS ${ }^{1}$, MIRIAM IDALIA TORRES-RUIZ ${ }^{2}$, \\ LUIS ARIEL WALLER-GONZÁLEZ ${ }^{2}$, JOSÉ DE JESÚS RAMÍREZ-GARCÍA ${ }^{2}$, JAVIER TORRES-LÓPEZ ${ }^{3}$, \\ JAVIER VENTURA-JUÁREZ ${ }^{4}$, ELIZABETH VERÓNICA MORENO-CÓRDOVA ${ }^{1}$, JUAN ERNESTO LÓPEZ-RAMOS ${ }^{1}$, \\ MARTIN HUMBERTO MUÑOZ-ORTEGA ${ }^{5}$, MARÍA EUGENIA VARGAS-CAMAÑO ${ }^{6}$ \\ and RODOLFO GONZÁLEZ-SEGOVIA ${ }^{1}$
}

\author{
${ }^{1}$ Departamento de Microbiología, Universidad Autónoma de Aguascalientes, Aguascalientes Ags, CP 20131; \\ ${ }^{2}$ Departamento de Endoscopia, Centro Médico Nacional 20 de Noviembre ISSSTE, Ciudad de México, CP 03229; \\ ${ }^{3}$ Unidad de Investigación Médica en Enfermedades Infecciosas y Parasitarias UMAE, Hospital de Pediatría, \\ IMSS, Ciudad de México, CP 06720; ${ }^{4}$ Departamento de Morfología; ${ }^{5}$ Departamento de Química, \\ Universidad Autónoma de Aguascalientes, Aguascalientes Ags, CP 20131; \\ ${ }^{6}$ Servicio de Inmunología Clínica y Alergía, Centro Médico Nacional \\ 20 Noviembre ISSSTE, Ciudad de México, CP 03229, México
}

Received June 7, 2019; Accepted January 17, 2020

DOI: $10.3892 / b r .2020 .1285$

\begin{abstract}
Programmed death-ligand 1 (PD-L1) and ICOS-L (also referred to as B7 homolog 1 and 2, respectively) modulate the immune inflammatory response. The aim of the present study was to examine the expression levels of these inflammatory mediators in two groups of patients with an Helicobacter pylori (H. pylori) infection; patients with and without gastric cancer. The association between bacterial virulence factors, CagA and VacA, was also examined, as well as their correlation with the inflammatory profile. Endoscopy analysis indicated that 18 patients suffered from cancer and 28 patients suffered from other gastric pathologies. PCR and reverse transcription-quantitative PCR were used to analyze gastric biopsies and determine the expression levels of the inflammatory modulators PD-L1 and ICOS-L, transcription factors, cytokines and other genes associated with inflammation and pathogenicity. All 46 patients were determined positive for markers of $H$. pylori. Patients with stomach cancer had lower levels of ICOS-L $(\mathrm{P}<0.05)$ and GATA3 $(\mathrm{P}<0.01)$, a negative correlation between CagA and IL-17 $(\mathrm{P}<0.05)$, a positive correlation between CagA and IL-10 $(\mathrm{P}<0.05)$, a negative correlation between $v a c A-m l$ and retinoid orphan receptor $\gamma \mathrm{t}$ $(\mathrm{ROR} \gamma \mathrm{t})(\mathrm{P}<0.001)$, and a positive correlation between $\mathrm{ROR} \gamma \mathrm{t}$
\end{abstract}

Correspondence to: Dr Rodolfo González Segovia, Departamento de Microbiología, Universidad Autónoma de Aguascalientes, Av. Universidad 940, Cd Universitaria, Aguascalientes Ags, CP 20131, Mexico

E-mail: rgonzals@correo.uaa.mx

Key words: programmed death-ligand 1, ICOS-L, gastric cancer, Helicobacter pylori, retinoid orphan receptor $\gamma \mathrm{t}$, IL-17, vacA-m1 and ICOS-L $(\mathrm{P}<0.001)$. The reduced levels of ICOS-L and GATA3 along with the negative correlation between CagA and IL-17, and between $v a c A-m l$ and ROR $\gamma$ t were all associated with an increased risk of gastric cancer in the present cohort.

\section{Introduction}

Helicobacter pylori (H. pylori) is present in the stomach of $\sim 50 \%$ of the population worldwide (1) and is considered to be the primary cause of chronic gastritis, gastric cancer and peptic ulcers (2). Around $89 \%$ of non-cardia gastric cancer cases, representing $78 \%$ of all gastric cancer case, are now estimated to be attributable to chronic H. pylori infection (3). Gastric cancer is among the five most common types of malignant tumors, and has the second highest cause of cancer-associated death worldwide (4). However, only $1-3 \%$ of the individuals with an $H$. pylori infection develop gastric cancer (5), as this pathology is dependent on the virulence of the bacteria, the environment and genetic factors of the host $(6,7)$. For instance, common variable immunodeficiency (CVID) syndrome is associated with a 45-fold increase in the risk of gastric cancer and a 30 -fold increase in the risk of gastric lymphoma (8). Although the etiology of CVID is not completely understood, in adults it is associated with deletion of a gene which encodes the inducible T-cell co-stimulator ICOS (9), which is expressed by T-cells when activated by their antigen. The only known ligand of ICOS (ICOS-L) is expressed constitutively by B lymphocytes (10). The interaction between ICOS:ICOS-L serves an important role in mediating the cooperation between $\mathrm{T}$ and $\mathrm{B}$ cells, as well as promoting the terminal differentiation of B cells to plasma B cells. ICOS activation induces the secretion of IL-4, IL-5, IL-6, IL-10, IL-21, tumor necrosis factor-a and interferon gamma (IFN- $\gamma$ ). In doing so, ICOS co-induces the secretion of interleukins and activates the function of Th1, 
Th2 and Th17 cells $(11,12)$. Patients with deletion of ICOS have a reduced number of naïve $B$ cells and memory cells, and low levels of serum antibodies, but do not exhibit a change in antibody isotype (9).

Another molecule which modulates the immune response is programmed death-ligand 1 ( $\mathrm{PD}-\mathrm{L} 1$; also known as $\mathrm{B} 7$ homolog 1). Encoded by the CD274 gene, PD-L1 activates a membrane receptor of programmed death 1 (PD-1). The PD-L1:PD-1 axis maintains the balance between tolerance and autoimmunity. A deficiency or excess in the function of PD-1 can result in various diseases, for example arthritis and lupus (13). One mechanism of regulating the expression of PD-L1, is binding of STAT3 to its promoter (14). Research has shown that in patients with tumors, upregulation of hypoxia-inducible factor $1 \alpha$ is associated with elevated levels of PD-L1 (15). PD-L1 functions primarily in a microenvironment enriched with lactate (16).

In relation to the virulence of $H$. pylori, the most studied molecule is the cytotoxin associated gene ( $\mathrm{Cag} A)$, which is translocated by the type IV secretion system of $H$.pylori into gastric cells, generating intracellular signals that facilitate malignancy (17). Individuals have an increased risk of developing gastric cancer if they express cagA+ instead of cagA-, and the strains of $H$. pylori that carry CagA are associated with an increased risk of developing chronic gastritis or peptic ulcers, as demonstrated in a meta-analysis (18). CagA is considered the primary virulence factor of $H$. pylori, and results in the downregulation of the inflammatory modulator ICOS-L, the attenuation of which occurs through the P70-S6 kinase signaling pathway in gastric epithelial cells (19).

Vacuolating cytotoxin A is another virulence mechanism of $H$. pylori correlated with gastric cancer $(20,21)$. The DNA sequence analysis of the vacA gene shows a mosaic structure comprising allelic variations with different biological activity, resulting in the $\mathrm{s} 1$ and $\mathrm{m} 1$ regions as the two regions most frequently associated with peptic ulcers and an increased risk of gastric cancer (22). One of the mechanisms attributed to VacA is its interference with IL-2 production and IL-2 receptor (IL-2R) expression, which in turn reduces the proliferation of $\mathrm{T}$ lymphocytes (23). In mice, purified VacA results in the loss of gastric epithelial cells in vivo and in vitro by increasing apoptosis, which is initiated through the release of mitochondrial cytochrome $\mathrm{C}$ and the activation of Caspase 3 (24).

A meta-analysis recently suggested that the presence of the $v a c A-s l$ and $v a c A-m l$ genotype results in a greater risk of gastric cancer and account for a $33.4 \%$ and 2.08 -fold increase, respectively, with an age-standardized rate (ASR) of 11-19 cases per 100,000 individual. A 40.2 and $66.6 \%$ increase, respectively, of gastric cancer was reported for a group with an ASR $<10$ per 100,000. Therefore, the vacA-ml genotype of $H$. pylori appears to be more potent than $v a c A-s l$ for inducing gastric cancer (25).

In the present study, the differences in the mRNA expression levels of cytokines, master transcription factors associated with the T-cell profile, and the co-immunomodulatory molecules PD-L1 and ICOS-L in two groups of patients infected with $H$. pylori, those with and without gastric cancer were examined. Additionally, the correlation between each group, the polymorphisms of $v a c A$ and the presence of $\operatorname{cagA}$ was assessed. The aim of the present study was to determine effect the co-modulating molecules, ICOS-L and PD-L1, conferred on the immune response of patients infected with $H$. pylori with or without gastric cancer.

\section{Materials and methods}

Patients. The present study was performed in the National Medical Center (Centro Médico Nacional 20 de November) of the ISSSTE Medical Service (a health plan for government workers) between June 2016 and August 2017. A total of 1,462 endoscopies were performed during this period on adults ( $>18$ years of age), and 46 patients exhibited signs of a gastric pathology. These patients were referred to our group. The patients were given a detailed description of the study and all patients provided written informed consent, in accordance with the Helsinki Declaration and the Ethics Committee of the National Medical Center (Centro Médico Nacional 20 de November) of the ISSSTE Medical Service. The protocol used in the present study was approved by the Bioethics Committee of the Autonomous University of Aguascalientes (approval no. CIB-UAA-26).

The patients were divided into two groups; those with cancer $(n=18)$, males $(n=10,55.56 \%)$, female $(n=8,44.44 \%)$, mean age $64.72 \pm 2.54$ years (age range $48-82$ ), and those without cancer $(n=28)$ males $(n=16,21.42 \%)$, female $(n=22$, $78.58 \%$ ), age mean $55.68 \pm 2.59$ years (age range 33-77). Of the patients without gastric cancer, a duodenal ulcer was present in 10 patients, whereas the other 18 patients exhibited various other types of gastritis (epidemiological variables shown in Table I).

Extraction of gastric biopsies. The endoscopy procedure was handled by an experienced endoscopist on a Jaw Radial Endoscopy apparatus $(160.24 \mathrm{~cm}$ in length with a $6 \mathrm{~mm}$ opening; Boston Scientific) and a 590 EG ZW (with a working channel $2.8 \mathrm{~mm}$ in diameter) (Fujinon; FUJIFILM, Inc.) with an EPX 4400 processor. By using the conventional brightfield endoscopy procedure, the mucus was carefully observed to detect visible alterations indicative of a gastropathy (for examples gastritis, gastric ulcers or duodenal ulcers) in patients with symptoms suggestive of these disorders. In individuals suspected of having gastric cancer, the neoplasm was examined to determine its characteristics and location. Gastric biopsies were obtained from the pyloric antrum and were placed in small vials containing TRIzol (Invitrogen; Thermo Fisher Scientific, Inc.) and ethanol for extraction of RNA and DNA, respectively. The samples were stored at $-40^{\circ} \mathrm{C}$ until required. Additional biopsies of the pyloric antrum were extracted and placed in $4 \%$ formaldehyde for histopathological confirmation using the Sydney protocol (26). In the event of a gastric neoplasm, a biopsy of the lesion was taken to perform histopathological analysis using hematoxylin and eosin staining (27).

DNA purification from gastric tissue. DNA was extracted using phenol-chloroform (28). Gastric tissue was homogenized with $500 \mu \mathrm{l}$ lysis buffer ( $2 \mathrm{mM}$ Tris-HCl, $10 \%$ SDS, $1 \mathrm{mM}$ EDTA and $1.5 \mu \mathrm{g} / \mu 1$ proteinase $\mathrm{K}$ ) and the sample was incubated at $65^{\circ} \mathrm{C}$ for $24 \mathrm{~h}$. Subsequently, $500 \mu \mathrm{l}$ phenol:isoamyl alcohol solution (24:1) was added and the 
Table I. Clinicopathological characteristics of the patients recruited in the present study.

\begin{tabular}{lccc}
\hline Clinicopathological characteristics & With cancer, $\mathrm{n}=18$ & Without cancer, $\mathrm{n}=28$ & P-value \\
\hline Age, mean \pm standard deviation (age range) & $64.72 \pm 2.547(48-82)$ & $55.68 \pm 2.594(33-77)$ & $0.0227^{\mathrm{a}}$ \\
Males, $\mathrm{n}(\%)$ & $10(55.56)$ & $6(21.42)$ & $0.0172^{\mathrm{a}}$ \\
Female, $\mathrm{n}(\%)$ & $8(44.44)$ & $22(78.58)$ & $0.0271^{\mathrm{a}}$ \\
Smoker, $\mathrm{n}(\%)$ & $8(44.45)$ & $6(32.14)$ & 0.4102 \\
Atrophy, $\mathrm{n}(\%)$ & $5(27.78)$ & $6(21.42)$ & 0.6314 \\
Non-Atrophy, $\mathrm{n}(\%)$ & $13(72.22)$ & $7(25)$ & 0.6314 \\
Type 2 diabetes, $\mathrm{n}(\%)$ & $3(16.66)$ & $10(35.71)$ & 0.7172 \\
High blood pressure, $\mathrm{n}(\%)$ & $3(16.66)$ & $12(42.85)$ & 0.1968 \\
Duodenal ulcer, $\mathrm{n}(\%)$ & $2(11.11)$ &
\end{tabular}

${ }^{\mathrm{a} P}<0.05$.

Table II. Primer sequences used to identify Helicobacter pylori positivity based on the presence of cagA and for analysis of the vacA polymorphisms.

\begin{tabular}{|c|c|c|c|c|c|}
\hline Author, year & Gene & Forward & Reverse & Product length & (Refs.) \\
\hline Abdi et al, 2016 & cag2-4 & $\begin{array}{l}\text { GGAACCCTAGTC } \\
\text { GGTAATG }\end{array}$ & ATCTTTGAGCTTGTCTATCG & $450 / 558$ & $(25)$ \\
\hline \multirow[t]{2}{*}{ Sipponen et al, 2011} & cagA1 & $\begin{array}{l}\text { TGGCAGTGGGTTAG } \\
\text { TCATAGCAG }\end{array}$ & $\begin{array}{l}\text { AGGACTCTTGCAGGCGTT } \\
\text { GGTG }\end{array}$ & 481 & $(26)$ \\
\hline & cagA2 & $\begin{array}{l}\text { ATAATGCTAAATTA } \\
\text { GACAACTTGAGCGA }\end{array}$ & $\begin{array}{l}\text { TTAGAATAATCAACAAACAT } \\
\text { CACGCCAT }\end{array}$ & 298 & \\
\hline \multirow[t]{2}{*}{ Luna, 1968} & G-Hp1/2 & $\begin{array}{l}\text { AAGCTTTTAGG } \\
\text { GGTGTTAGGGGTTT }\end{array}$ & $\begin{array}{l}\text { AAGCTTACTTTCTAACACTA } \\
\text { AACGC }\end{array}$ & 294 & (27) \\
\hline & G-H3/4 & $\begin{array}{l}\text { СTTTСТTCтC } \\
\text { AAGCGGTTGTC }\end{array}$ & CAAGCCATCGCCGGTTTTAGC & 252 & \\
\hline \multirow[t]{4}{*}{$\begin{array}{l}\text { Sambrook and Green, } \\
2012\end{array}$} & sl vacl & $\begin{array}{l}\text { GAAATACAAC } \\
\text { AAACACACCGC }\end{array}$ & GGCTTGTTTGAGCCCCCAG & 201 & (28) \\
\hline & $s 2 \mathrm{vacl}$ & $\begin{array}{l}\text { GAAATACAAC } \\
\text { AAACACACCGC }\end{array}$ & GGCTTGTTTGAGCCCCCAG & 228 & \\
\hline & $m 1$ Vac3 & $\begin{array}{l}\text { GGTCAAAAT } \\
\text { GCGGTCATGG }\end{array}$ & CATCAGTATTTCGCACCACA & 388 & \\
\hline & $m 2$ Vac4 & $\begin{array}{l}\text { CCAGGAAAC } \\
\text { ATTGCCGGCAAA }\end{array}$ & CATAACTAGCGCCTTGCAC & 346 & \\
\hline
\end{tabular}

mixture was centrifuged at $15,800 \mathrm{x}$ g for $15 \mathrm{~min}$ at $25^{\circ} \mathrm{C}$. The aqueous phase was separated, and a second extraction was performed using the supernatant with $500 \mu 1$ chloroform:isoamyl alcohol solution (24:1). The sample was centrifuged at $15,800 \mathrm{x}$ for $15 \mathrm{~min}$ at $25^{\circ} \mathrm{C}$ and the aqueous phase was collected. After precipitating the DNA present in the aqueous phase with $500 \mu \mathrm{l}$ isopropanol and centrifuging at $15,800 \mathrm{x}$ g for $5 \mathrm{~min}$ at $25^{\circ} \mathrm{C}$, the pellet was washed with $70 \%$ ethanol at $-20^{\circ} \mathrm{C}$ and resuspended in nuclease-free water free of chelating agents. DNA was quantified by spectrophotometry at $260 \mathrm{~nm}$ and its integrity was evaluated by electrophoresis on a $1.25 \%$ agarose gel.

Sequence typing of vacA and determination of cagA positivity. The genotypes of $H$. pylori with the presence/absence of $\operatorname{cag} A$ and distinct polymorphic regions for $v a c A$ ( $s 1 s 2$ or m1m2) were analyzed by endpoint PCR from DNA samples extracted from the gastric tissue. PCR was performed using a Platinum ${ }^{\circledR}$ PCR SuperMix (Invitrogen; Thermo Fisher Scientific, Inc.) on a Techne 3 Prime Base/02 thermocycler with the following thermocycling conditions: Denaturation at $95^{\circ} \mathrm{C}$ for $1 \mathrm{~min}$, annealing at $58^{\circ} \mathrm{C}$ for $30 \mathrm{sec}$ and extension at $72^{\circ} \mathrm{C}$ for $30 \mathrm{sec}$ for 40 cycles. The sequences the primers used are presented in Table II (29-32).

RNA extraction and reverse transcription $(R T)$. Total RNA was extracted using the organic protocol with TRIzol (33). To eliminate genomic DNA contamination, digestion of DNA was performed using 2 U DNase I (DNase amplification grade) (Invitrogen; Thermo Fisher Scientific, Inc.) per $\mu \mathrm{g}$ RNA. The sample was incubated at room temperature for $15 \mathrm{~min}$. Subsequently, the enzyme was inactivated with $1 \mu \mathrm{l}$ 


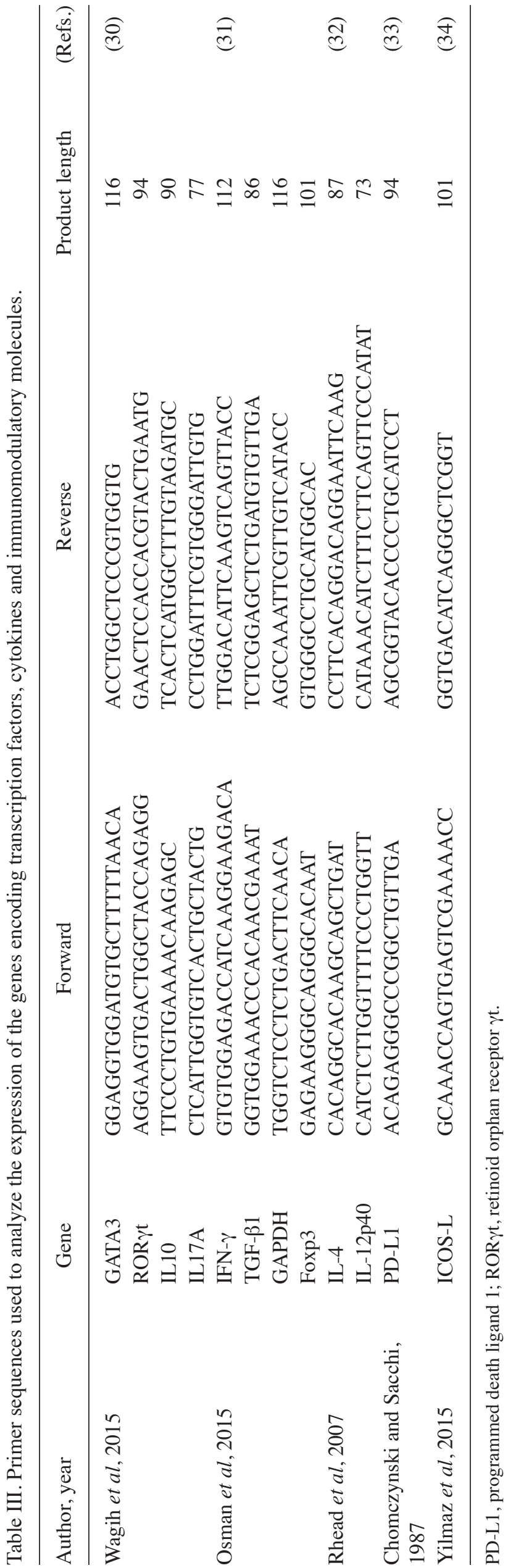

EDTA $(25 \mathrm{mM})$ and $10 \mathrm{~min}$ of heating at $65^{\circ} \mathrm{C}$. Total RNA was quantified by spectrophotometry at $260 \mathrm{~nm}$ and the integrity of the RNA was assessed using electrophoresis on a $1.2 \%$ agarose gel.

RT of total RNA was performed using a Superscript VILO kit (Invitrogen; Thermo Fisher Scientific, Inc.), according to the manufacturer's protocol. The resulting cDNA was quantified by spectrophotometry at $260 \mathrm{~nm}$ and the samples were diluted to a concentration of $400 \mathrm{ng} / \mu \mathrm{l}$. The samples were stored at $-20^{\circ} \mathrm{C}$ until further use.

Analysis of RNA expression in gastric biopsies. The RNA obtained from gastric tissue was evaluated by RT-quantitative (q)PCR using Express SYBR qPCR SuperMix Universal (Invitrogen; Thermo Fisher Scientific, Inc.). The expression levels of cytokines (IL-4, IL-10, IL-12, IL-17, IFN- $\gamma$ and TGF- $\beta$ ), the co-modulating molecules of the immune system (PD-L1 and ICOS-L), and the master transcription factors, including forkhead box P3 (Foxp3), GATA3, and the retinoid orphan receptor $\gamma \mathrm{t}(\mathrm{ROR} \gamma \mathrm{t})$. Analysis was performed on a StepOne $^{\mathrm{TM}}$ Real-Time PCR system (Applied Biosystems; Thermo Fisher Scientific, Inc.). The thermocycling conditions were: Initial denaturation, $50^{\circ} \mathrm{C}$ for $2 \mathrm{~min}$ and $95^{\circ} \mathrm{C}$ for $10 \mathrm{~min}$; followed by 50 cycles of denaturation at $95^{\circ} \mathrm{C}$ for $15 \mathrm{sec}$, and annealing and an extension at $60^{\circ} \mathrm{C}$ for $60 \mathrm{sec}$. All primers were acquired from T4 Oligo. The sequences of the primers used are presented in Table III (34-38). GAPDH was used as the normalization control. The differential expression of genes was calculated using the $2^{-\Delta \Delta \mathrm{Cq}}$ method (39).

Statistical analysis. The results from qPCR were examined on DataAssist ${ }^{\mathrm{TM}}$ Software version 3.01 (Applied Biosystems; Thermo Fisher Scientific, Inc.) using the $\mathrm{Cq}$ values for relative expression. The relative expression of mRNA was compared between patients with and without cancer to determine the significance of differences using a Mann-Whitney U test and SPSS version 20 (IBM Corp.) and multiple comparisons were evaluated using a Kruskal-Wallis test with a Dunn's post-hoc. This test is suitable for comparison of two unpaired groups of continuous variables that are not normally distributed. $\mathrm{P}<0.05$ was considered to indicate a statistically significant difference. To analyze if there was a relationship between the mRNA expression levels of the various genes within each group, a Spearman's Rho $(\rho)$ value was calculated (40). The correlation was considered either positive/negative and either high/medium/low (high, $\rho$ value of $0.7-0.9$; medium, $\rho$ value of $0.5-0.7$; low $\rho$ value $<0.5$ ) according to the scale described by Mukaka (41).

\section{Results}

Prevalence of the cagA and vacA genotype in gastric biopsies. All 46 biopsies were positive for ureC (a marker for H.pylori) and vacA. Only 18 biopsies were positive for $\operatorname{cag} A$ (39.1\%). Regarding $v a c A$, the frequency of polymorphisms in the subregions $s l$ and $m l$ in the group of patients with gastric cancer was higher compared with the rest of the subregions (Table IV). It has been reported that polymorphisms in these subregions increase the risk of gastric cancer (25). The possible association between these polymorphisms with the 
Table IV. Frequency of two vacA polymorphisms and of positivity for $\operatorname{cag} A$ and $u r e C$ in patients with and without gastric cancer.

\begin{tabular}{lrrrrrrr}
\hline & & & $\begin{array}{c}s \text { regions } \\
\text { of vacA }\end{array}$ & & \multicolumn{2}{c}{$\begin{array}{c}m \text { regions } \\
\text { of vacA }\end{array}$} \\
Groups & ureC & cagA & $s 1$ & $s 2$ & & $m 1$ & $m 2$ \\
\hline Cancer & 18 & 10 & 14 & 1 & 9 & 4 \\
Without Cancer & 28 & 8 & 16 & 2 & 14 & 12 \\
Total & 46 & 18 & 30 & 3 & 23 & 16 \\
\hline
\end{tabular}

expression of the mRNA of cytokines, nuclear transcription factors and co-modulating molecules related to the gastric pathology caused by $H$. pylori was further analyzed.

Analysis of mRNA expression in gastric biopsies. The expression of cytokines, transcription factors and co-modulating molecules of the immune system was determined using RT-qPCR. The expression levels of ICOS-L were significantly reduced in patients with cancer (Fig. 1A). Additionally, there was a lower level of ICOS-L relative to PD-L1, represented by the ratio PD-L1/ICOS-L, although this decrease was not significant (Fig. 1B)

The relative expression of the master transcription factors was higher with the phenotype of regulatory T cell (Treg), Th17 and GATA3 in the patients without cancer. The difference in the expression of Foxp3 $(\mathrm{P}=0.063)$ and ROR $\gamma \mathrm{t}(\mathrm{P}=0.060)$ between patients with and without gastric cancer was not significant; however, the difference in the expression of GATA3 was significant between the two groups. ( $\mathrm{P}<0.01$; Fig. 1C).

The expression levels of IL-4, IL-10, IL-12 and IL-17, IFN- $\gamma$ and TGF- $\beta$ were similar between the two groups. The expression levels of IL-4 in the Th2 profile were decreased in patients with gastric cancer, but the difference was not significant $(\mathrm{P}=0.07$; Fig. 1D).

Spearman's rank correlation coefficient. Spearman's bivariate correlation analysis of immune- and virulence-related variables in patients with and without cancer are presented in Table V. Patients without cancer showed a high positive correlation between ICOS-L and PD-L1 $(\rho=0.707)$, IL-4 $(\rho=0.719)$ and IL-12A $(\rho=0.712)$; a moderate positive correlation with ROR $\gamma \mathrm{t}(\rho=0.687)$, GATA-3 $(\rho=0.561)$ and Foxp3 $(\rho=0.530)$; and low positive correlation with TGF- $\beta(\rho=0.481)$ and IL-17 $(\rho=0.411)$. Patients with cancer exhibited a high positive correlation between ICOS-L and IL-12 $(\rho=0.772)$, ROR $\gamma \mathrm{t}(\rho=0.760)$ and IL-10 $(\rho=0.708)$; a moderate positive correlation with GATA3 $(\rho=0.689)$, IFN- $\gamma(\rho=0.637)$, PD-L1 $(\rho=0.610), v a c A-m 2(\rho=0.567)$ and IL-4 $(\rho=0.566)$; and a low positive correlation factor with Foxp3 $(\rho=0.490)$.

Patients without cancer exhibited a high positive correlation between PD-L1 and ICOS-L $(\rho=0.707)$; a moderate positive correlation with IL-4 $(\rho=0.668)$, IL-17A $(\rho=0.570)$, Foxp3 $(\rho=0.551)$ and TGF- $\beta(\rho=0.525)$; and a low positive correlation with IFN- $\gamma(\rho=0.454)$ and IL-10 $(\rho=0.428)$. For the patients with cancer, there was a high positive correlation between PD-L1 and IL-10 $(\rho=0.789)$, IL-12A $(\rho=0.789)$ and GATA3 $(\rho=0.757)$; and a low positive correlation with IFN- $\gamma$ $(\rho=0.485)$ and Foxp3 $(\rho=0.483)$.

Patients without cancer demonstrated a high positive correlation between ROR $\gamma$ t and IL-12A $(\rho=0.772)$, IL-4 $(\rho=0.737)$ and Foxp3 ( $\rho=0.708)$; a moderate positive correlation with IL-17A $(\rho=0.603)$ and PD-L1 $(\rho=0.549)$; and a low positive correlation with TGF- $\beta(\rho=0.408)$. Patients with cancer exhibited a high positive relation of ROR $\gamma \mathrm{t}$; a moderate positive correlation with IL-12A $(\rho=0.623)$, vacA-m2 $(\rho=0.598)$ and GATA3 $(\rho=0.522)$; and a low positive correlation with IL-10 $(\rho=0.488)$. A high negative correlation was observed between ROR $\gamma t$ and $v a c A-m l(\rho=-0.756)$.

In the patients without cancer, there was a high positive correlation between Foxp3 and IL-12A $(\rho=0.784)$ and IL-4 $(\rho=0.715)$; a moderate positive correlation with IL-17A $(\rho=609)$, IFN $-\gamma(\rho=0.585)$ and IL-10 $(\rho=0.579)$; and a low positive correlation with TGF- $\beta(\rho=0.457)$. In patients with cancer, there was a moderate correlation between Foxp3 and IL-12 $(\rho=0.659)$ and IL-10 $(\rho=0.569)$; and a low positive correlation with GATA3 $(\rho=0.493)$.

Patients without cancer had a moderate positive correlation between IL-17A and IL-10 ( $\rho=0.690)$, TGF- $\beta(\rho=0.637)$, IFN- $\gamma$ $(\rho=0.572)$, IL-4 $(\rho=0.565)$ and IL-12A $(\rho=0.530)$. In patients with cancer, there was only a low positive correlation between IL-17A and IL-10 $(\rho=0.493)$ and a moderate negative correlation with CagA $(\rho=-0.537)$.

Patients without cancer exhibited a moderate positive correlation between TGF- $\beta$ with IFN- $\gamma(\rho=0.676)$ and IL-10 ( $\rho=0.621)$; and a low positive correlation with IL-4 $(\rho=0.413)$. Patients with cancer only showed a moderate positive correlation between TGF- $\beta$ and IFN- $\gamma(\rho=0.581)$.

Patients without cancer exhibited a high positive correlation between IL-10 with IFN- $\gamma(\rho=0.775)$; a moderate positive correlation with TGF- $\beta(\rho=0.621)$, Foxp3 $(\rho=0.579)$. Patients with cancer demonstrated a high positive correlation between IL-10 a moderate positive correlation with IL-12A $(\rho=0.696)$, GATA3 $(\rho=0.672)$ and $v a c A-m 2(\rho=0.630)$.

\section{Discussion}

In the present study, the presence of $H$. pylori in gastric biopsies from patients with and without gastric cancer was examined, as well as the correlation between the development of this disorder and the presence of virulence factors, CagA and VacA (42), including the polymorphisms of vacA ( $s 1$, $s 2, m 1$ and $m 2$ ) (22). The $s 1 m 1$ polymorphism of $v a c A$ was found to be the most frequently observed polymorphism in the participants, consistent with a previous study on an adult population in Mexico (43).

The host factors which may affect the elimination or proliferation of $H$. pylori (44) were also analyzed in the present study. Gastric biopsies were obtained to determine the mRNA expression levels of interleukins, master transcription factors and co-modulators of the immune response. RT-qPCR analysis showed significantly lower relative mRNA expression levels of the co-activating molecule ICOS-L in patients with cancer compared with patients without cancer. ICOS-L is the only known ligand for ICOS, a receptor which activates 


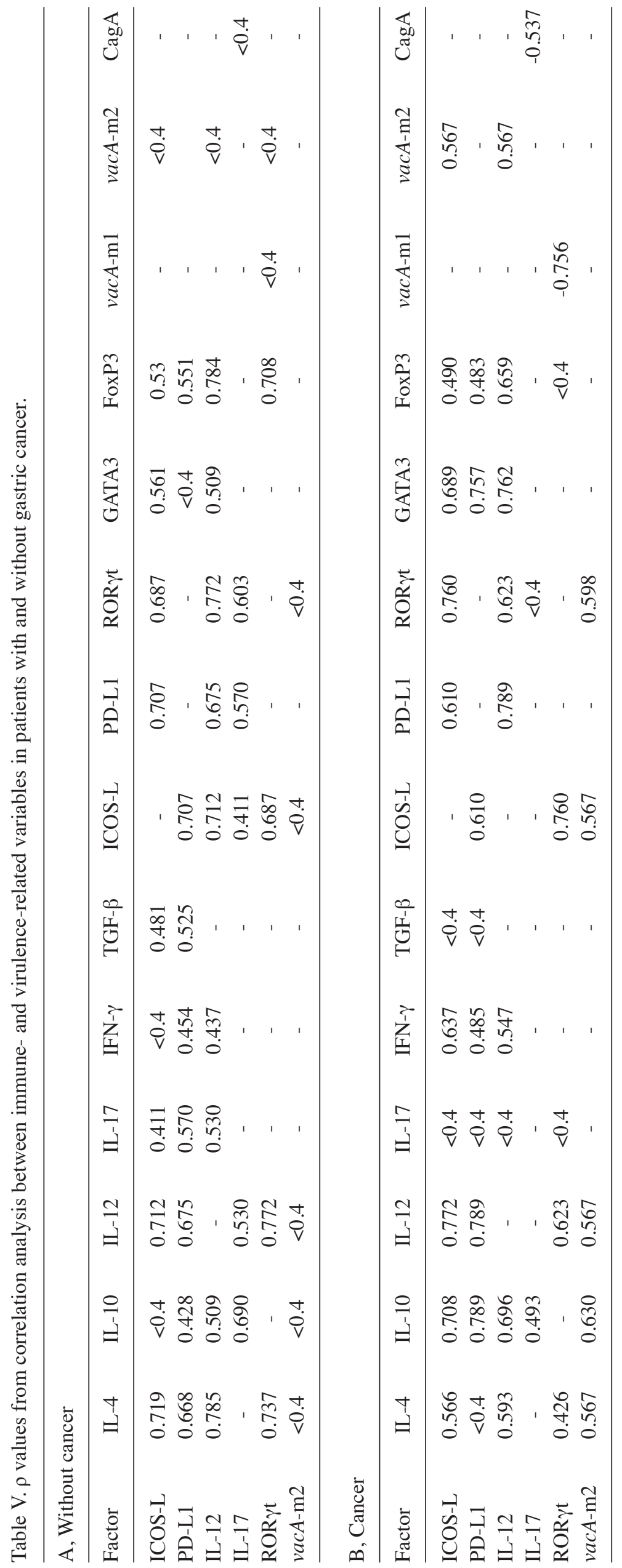




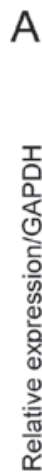

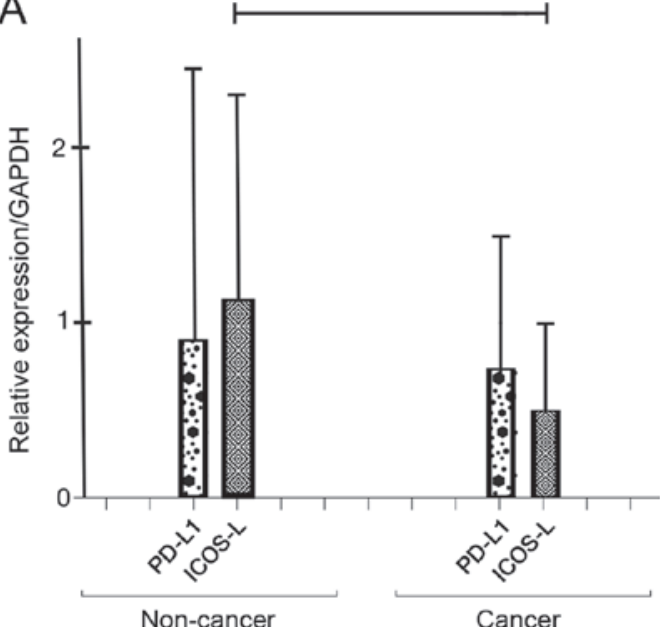

C

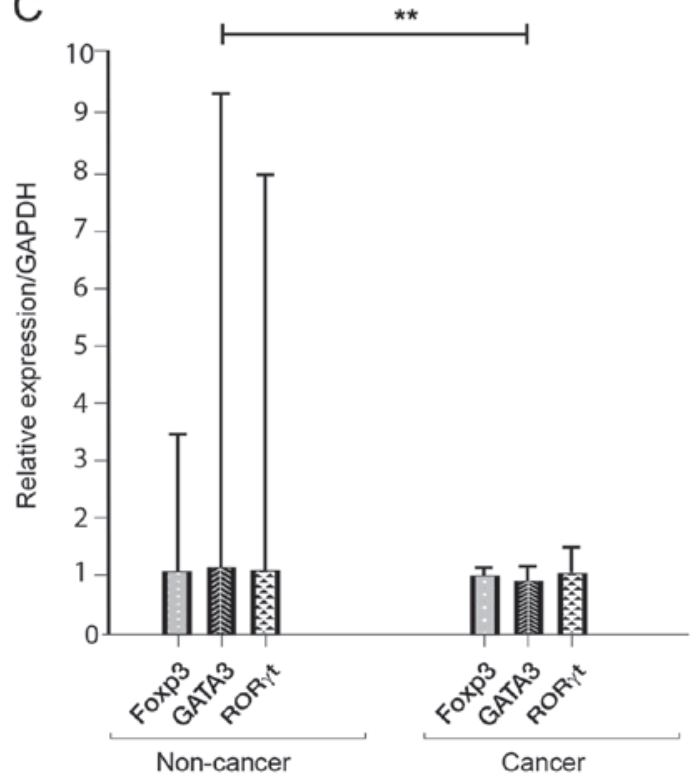

$\mathrm{B}$

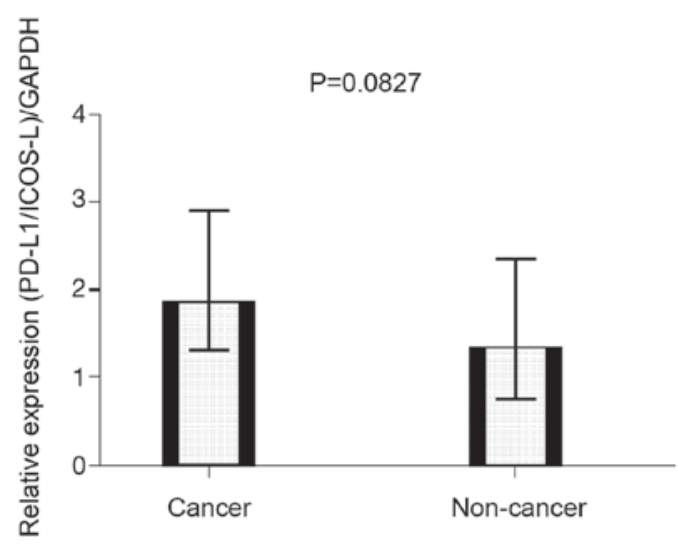

D

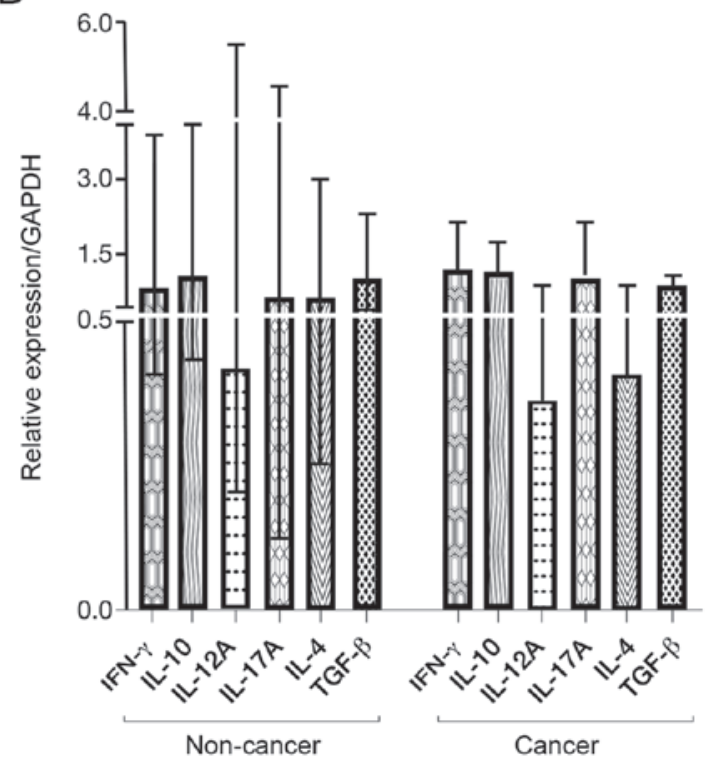

Figure 1. Analysis of cytokine, transcription factors and immunomodulatory molecules expression levels in gastric biopsies. (A) Relative mRNA expression levels of PD-L1 and ICOS-L in patients with and without cancer. ${ }^{*} \mathrm{P}<0.05$. (B) Ratio of PD-L1/ICOS-L expression in patients with and without gastric cancer. (C) Relative expression of Foxp-3, GATA3 and ROR $\gamma$ t in patients with and without gastric cancer. ${ }^{* *} \mathrm{P}<0.01$. (D) Relative expression of IL-4, IL-10, IL-12, IL-17, IFN- $\gamma$ and TGF- $\beta$ in patients with and without gastric cancer. Data are expressed as the median \pm the interquartile range. PD-L1, programmed death ligand 1; ROR $\gamma$ t, retinoid orphan receptor $\gamma \mathrm{t}$.

various inflammatory pathways implicated in the elimination of $H$.pylori (11).

In the patients with cancer, the mRNA expression levels of the master transcription factor GATA3 was significantly reduced. GATA3 promotes the differentiation of T-cells into Th2 cells (45). The reported negative association between allergies and $H$. pylori infection can be explained, at least in part, by hygiene theory, which is based on the fact that microbial infections protect against allergic processes by suppressing T-helper 2 immune responses (46). The inflammation caused by $H$.pylori can induce an imbalance in $\mathrm{T}$ helper cells between the Th1- and Th2-types in the gastric mucosa (47). When stimulated ex vivo with $H$. pylori, dendritic cells of peripheral blood (derived from mononuclear cells) exhibit increased production of IL-12 (48).

The differentiation to the Th1 phenotype was determined based on the expression of IL-12A and IFN- $\gamma$ which constitute the most important cytokines produced by Th1 cells and underlie the suppression of GATA-3 in T-cells (49); a result observed in the present study as well in the patients with cancer. The suppression of GATA-3 may be explained by the fact that the Helicobacter pylori neutrophil-activating protein HP-NAP is an antagonist of TLR2 and stimulates neutrophils and monocytes to produce inflammatory cytokines associated with Th1 lymphocytes (50). Bagheri et al (51-53) showed that in the evolution of gastric pathologies caused by $H$. pylori infection, there is a dynamic change in the phenotypes of inflammatory cells of the innate and adaptive immune system, as well as in the underlying mechanisms of regulation and damage repair, performed by cells of the immune system and their mediators, with significant differences in the levels of expression of inflammatory and anti-inflammatory cytokines between healthy patients (no $H$. pylori infection) compared with patients infected with $H$. pylori, and at different stages of gastric infection. 
To improve our understanding of the microenvironment in the gastric tissues, Spearman's rank correlation coefficient analysis was performed between various factors of the immune response: Co-modulating molecules, cytokines, transcription factors and variants of the virulent factors of $H$. pylori. In the participants without cancer, there was a positive correlation between ICOS-L and IL-17A. The latter cytokine represents the Th17 group, which is associated with the elimination of $H$. pylori (54). This correlation did not exist in the patients with cancer, perhaps due to the phenomenon described by Downs (55); the microenvironment of the tumor has a mechanism for evading the immune response through the transdifferentiation of the lymphocytes from a $\mathrm{Th} 17^{+} / \mathrm{Foxp}^{-}$phenotype to a $\mathrm{Th} 17^{+} / \mathrm{Foxp}^{+}$phenotype, resulting in an increase in the population of Treg cells as well as anti-inflammatory cytokines.

Unlike the patients without cancer, those with cancer showed a positive correlation between ICOS-L and IL-10 (Treg) and IFN- $\gamma$ (Th1). It has been reported that signaling through ICOS-L can have a direct effect on dendritic cells via phosphorylation of p38-MAPK and decrease the expression of IL-10/FoxP3 in cell lines (56). In the results of the present study, the high correlation between IL-10 and ICOS-L observed in patients with cancer suggests a possible alteration of the p38-MAPK pathway.

The expression of the transcription factor GATA3 was significantly different between the two groups. The most notable positive correlation of GATA 3 was with IL-4 (the primary cytokine of the Th2 inflammatory phenotype) in the patients without cancer. For the other transcription factors analyzed by RT-qPCR (ROR $\gamma$ t and Foxp3), the relative expression levels of their mRNA was lower in the patients with cancer, but the difference was not significant. A key correlation, reported for the first time in the present study, to our knowledge, was the high negative correlation between the ROR transcription factor and the $\mathrm{m} 1$ vacA polymorphism, additionally a negative correlation between IL-17A and CagA was identified. Establishing that both proteins interfere with the Th17 inflammatory profile activation axis. The previous result indicates a possible synergy of both proteins to interfere with the axis of activation of the Th17 inflammatory profile. The synergy between CagA-VacA has only been documented to generate damage to gastric cells and facilitate iron acquisition (57).

Additionally, there was a moderate negative correlation between IL-17A and the oncoprotein CagA in the patients with (but not without) cancer. The same inverse association has been explained as a reduction in ICOS-L expression in gastric epithelial cells through CagA-induced activation of the mTOR kinase p70 S6 signaling pathway, associated with a reduction in Th17 cells (19). The mechanism of evasion used by $H$. pylori may be coordinated by the polymorphism of the middle region of $v a c A(\mathrm{ml})$ and the presence of the CagA protein to decrease the Th17 phenotype, and thus allow the bacteria to survive and proliferate in the host. The genotypes of $H$. pylori with these characteristics thus constitute an increased risk of gastric cancer. A meta-analysis revealed that $m l$ of $v a c A$ is the greatest risk factor for gastric cancer (25).

In the participants without cancer, IL-17A exhibited a high correlation with IL-10, TGF- $\beta$, Foxp3 and ROR $\gamma$ t.
Downs-Canner et al (55) showed that Th17 lymphocytes are dependent on TGF- $\beta$ for their differentiation. Furthermore, plasticity has been described for the transdifferentiation of Th17 cells to Th17-IL-17neg-Foxp3 ${ }^{+}$cells, which is induced by the microenvironment of tumoral tissue (55). The significant correlation shown between IL-17A and Foxp3 in healthy tissue establishes a balance in the inflammatory/anti-inflammatory response, whereas in patients with cancer, the expression of Foxp3 with anti-inflammatory function, predominates in the tumor microenvironment.

Similarly, in the patients without (but not with) cancer, there a high positive correlation between ROR $\gamma \mathrm{t}$ and Foxp3. There is an antagonism between tumor tissue and Foxp3 T-cells, which has been reported for ROR $\gamma \mathrm{t}$ in mice (58). Recently it was documented that in the microenvironment of tumor tissue, a reduced number of Foxp $3^{+} \mathrm{T}$-cells resulted in a change in the phenotype of Foxp3 $3^{+} \mathrm{T}$-cells by the gene of the master transcription factor ROR $\gamma \mathrm{t}$ (55).

There was a very high correlation between TGF- $\beta$ and IFN- $\gamma$ and a high correlation between TGF- $\beta$ and IL-17A in the patients without stomach cancer. The co-cultivation of $\mathrm{CD}^{+} \mathrm{T}$-cells and macrophages was previously demonstrated to increase the secretion of IFN- $\gamma$ and IL-17A. When infected with $H$. pylori, these cells exhibited upregulated expression of ROR $\gamma \mathrm{t}$ and an increase in the number of Th17 cells (59). The correlation between TGF- $\beta$ and ROR $\gamma \mathrm{t}$, IL-17A, Foxp3 and IL-10 was only observed in the patients without cancer. Additionally in the patients without cancer, a correlation was also observed between TGF- $\beta$ and the two co-modulating molecules of the inflammatory response (ICOS-L and PD-L1).

ROR $\gamma \mathrm{t}$ is the master transcription factor for the differentiation of T-cells to Th17. Similarly, IL-6 and TGF- $\beta$ concomitantly serve an important roles in initiating differentiation (58). It is thus hypothesized that if a chronic infection results in the transformation of tumor cells, the correlation between TGF- $\beta$ and cytokines, including transcription factors, may be lost. In the patients with cancer in the present study, TGF- $\beta$ was only correlated with cytokines, and moderately with IFN- $\gamma$.

Of the polymorphisms of $v a c A$, only the $m 2$ polymorphism showed a high positive correlation with ROR $\gamma$ t, IL-12A, IL-4 and the co-stimulatory molecule ICOS-L, in patients with cancer. Notably, a meta-analysis showed an inverse correlation between the vacA-m2 polymorphism and the risk of gastric cancer (25). In the present study, cytokines and transcription factors were positively correlated with the vacA-m2 polymorphism, suggesting that the cytokines were associated with elimination of $H$. pylori and protection against gastric cancer.

In patients with gastric cancer, IL-10 was the anti-inflammatory cytokine which exhibited the highest correlation with the co-inhibitory molecule PD-L1 and with IL-12A; whereas in the patients without cancer, IFN- $\gamma$ and IL-17A exhibited the highest correlations with IL-10.

According to a previous study, H. pylori infection deregulates the expression of PD-L1, and the primary cytokine secreted during infection (principally by dendritic cells) is IL-10. The levels of IL-12A and IFN- $\gamma$ are increased only if the dendritic cells are treated with CD40L (60). H. pylori 
is capable of stimulating IL-23 secretion, which belongs to the family of IL-12A, and stimulates the production of IL-17 from TH-17 cells. However, following prolonged stimulation, the capacity of dendritic cells to produce IL-12A is reduced (61).

The results of the present study suggest that the evasion of the immune system by $H$.pylori occurs predominantly through the downregulation of the expression of ICOS-L in individuals with gastric cancer. These results suggest a coordination of the virulence factors cagA and vacA of $H$. pylori (particularly the $m l$ polymorphism of $v a c A$ ) to inhibit the differentiation of cells to the inflammatory Th17 phenotype.

In conclusion, the relative mRNA expression levels of the co-activating molecules ICOS-L and GATA3 (the master transcription factor for Th2 phenotype) were significantly lower in patients with cancer compared with patients without cancer. To the best of our knowledge, the present study is the first to show a high inverse correlation between the $m 1$ polymorphism of $v a c A$ and the master transcription factor ROR $\gamma$ t. Additionally, a previously described negative correlation between $\operatorname{cag} A$ and IL-17A was confirmed (55). Based on these results, it is hypothesized that vacA-ml and $c a g A$ coordinate the inhibition of the inflammatory response of Th17 cells. There was no correlation between TGF- $\beta$ and other cytokines or transcription factors in the patients with cancer. TGF- $\beta$ and IL- 6 are essential for the differentiation of the Th17 phenotype. The present study focused on correlations between the factors involved in the immune system, $H$. pylori and gastric cancer, showing novel associations of bacterial virulence factors and possible points of modulation of the inflammatory response. These results may highlight potential avenues for the design, diagnosis and therapeutics in oncological pathologies

\section{Acknowledgements}

We would like to thank Dr Ricardo Leopoldo Guido Bayardo of the Centro Médico Nacional 20 de Noviembre ISSSTE (Ciudad de México) for providing the facilities to collect clinical samples.

\section{Funding}

This study was funded by the Universidad Autónoma de Aguascalientes (Institutional registration no. PIBB17-3) in collaboration with the Centro Médico Nacional 20 de Noviembre ISSSTE.

\section{Availability of data and materials}

The datasets used and/or analyzed during the present study are available from the corresponding author on reasonable request.

\section{Authors' contributions}

The present study was performed by RGS and JGEC. Patient management was performed by EVMC, JTL, MITR, LAWG and RGJJ. Samples analysis was performed by MECV and JVJ. PCR analysis was performed by JGEC, MHMO and MEVC.
Statistics analysis was performed by JELR and JGEC. The literature review, manuscript and references was performed by JGEC and RGS. All authors have read and approved the final version of the manuscript.

\section{Ethics approval and consent to participate}

All patients provided written informed consent, in accordance with the Helsinki Declaration and the Ethics Committee of the National Medical Center (Centro Médico Nacional 20 de November) of the ISSSTE Medical Service. The protocol used in the present study was approved by the Bioethics Committee of the Autonomous University of Aguascalientes (approval no. CIB-UAA-26)

\section{Patient consent for publication}

Not applicable.

\section{Competing interests}

The authors declare that they have no competing interests.

\section{References}

1. Hooi JKY, Lai WY, Ng WK, Suen MMY, Underwood FE, Tanyingoh D, Malfertheiner P, Graham DY, Wong VWS, Wu JCY, et al: Global prevalence of helicobacter pylori infection: Systematic review and meta-analysis. Gastroenterology 153: 420-429, 2017.

2. Wang C, Yuan Y and Hunt RH: The association between Helicobacter pylori infection and early gastric cancer: A meta-analysis. Am J Gastroenterol 102: 1789-1798, 2007.

3. IARC Helicobacter pylori Working Group: Helicobacter pylori eradication as a strategy for preventing gastric cancer. IARC Working Group Reports, No. 8. IARC, Lyon, 2014.

4. Jemal A, Bray F, Center MM, Ferlay J, Ward E and Forman D: Global cancer statistics. CA Cancer J Clin 61: 69-90, 2011.

5. Yakirevich E and Resnick MB: Pathology of gastric cancer and its precursor lesions. Gastroenterol Clin North Am 42: 261-284, 2013.

6. Salama NR, Hartung ML and Muller A: Life in the human stomach: Persistence strategies of the bacterial pathogen Helicobacter pylori. Nat Rev Microbiol 11: 385-399, 2013.

7. Cover TL and Blaser MJ: Helicobacter pylori in health and disease. Gastroenterology 136: 1863-1873, 2009.

8. Kinlen LJ, Webster AD, Bird AG, Haile R, Peto J, Soothill JF and Thompson RA: Prospective study of cancer in patients with hypogammaglobulinaemia. Lancet 1: 263-266, 1985.

9. Salzer U, Maul-Pavicic A, Cunningham-Rundles C, Urschel S, Belohradsky BH, Litzman J, Holm A, Franco JL, Plebani A, Hammarstrom L, et al: ICOS deficiency in patients with common variable immunodeficiency. Clin Immunol 113: 234-240, 2004.

10. Hutloff A, Dittrich AM, Beier KC, Eljaschewitsch B, Kraft R, Anagnostopoulos I and Kroczek RA: ICOS is an inducible T-cell co-stimulator structurally and functionally related to CD28. Nature 397: 263-266, 1999.

11. Burugu S, Dancsok AR and Nielsen TO: Emerging targets in cancer immunotherapy. Semin Cancer Biol 52: 39-52, 2018.

12. Wikenheiser DJ and Stumhofer JS: ICOS Co-stimulation: Friend or foe? Front Immunol 7: 304, 2016.

13. Wang Y, Wang H, Yao H, Li C, Fang JY and Xu J: Regulation of PD-L1: Emerging routes for targeting tumor immune evasion. Front Pharmacol 9: 536, 2018.

14. Marzec M,Zhang Q, Goradia A, Raghunath PN,Liu X, Paessler M, Wang HY, Wysocka M, Cheng M, Ruggeri BA and Wasik MA: Oncogenic kinase NPM/ALK induces through STAT3 expression of immunosuppressive protein CD274 (PD-L1, B7-H1). Proc Natl Acad Sci USA 105: 20852-20857, 2008

15. Noman MZ, Desantis G, Janji B, Hasmim M, Karray S, Dessen P, Bronte V and Chouaib S: PD-L1 is a novel direct target of HIF- $1 \alpha$, and its blockade under hypoxia enhanced MDSC-mediated T cell activation. J Exp Med 211: 781-790, 2014. 
16. Feng J, Yang H, Zhang Y, Wei H, Zhu Z, Zhu B, Yang M, Cao W, Wang $\mathrm{L}$ and $\mathrm{Wu} \mathrm{Z}$ : Tumor cell-derived lactate induces TAZ-dependent upregulation of PD-L1 through GPR81 in human lung cancer cells. Oncogene 36: 5829-5839, 2017.

17. Chang WL, Yeh YC and Sheu BS: The impacts of H. pylori virulence factors on the development of gastroduodenal diseases. J Biomed Sci 25: 68, 2018.

18. Matos JI, de Sousa HA, Marcos-Pinto R and Dinis-Ribeiro M Helicobacter pylori CagA and VacA genotypes and gastric phenotype: A meta-analysis. Eur J Gastroenterol Hepatol 25: 1431-1441, 2013.

19. Lina TT, Pinchuk IV, House J, Yamaoka Y, Graham DY, Beswick EJ and Reyes VE: CagA-dependent downregulation of B7-H2 expression on gastric mucosa and inhibition of Th17 responses during Helicobacter pylori infection. J Immunol 191: 3838-3846, 2013.

20. Vacanti NM, Cheng H, Hill PS, Guerreiro JD, Dang TT, Ma M, Watson S, Hwang NS, Langer R and Anderson DG: Localized delivery of dexamethasone from electrospum fibers reduces the foreign body response. Biomacromolecules 13: 3031-3038, 2012.

21. de Figueiredo Soares T, de Magalhães Queiroz DM, Mendes EN, Rocha GA, Rocha Oliveira AM, Alvares Cabral MM and de Oliveira CA: The interrelationship between helicobacter pylori vacuolating cytotoxin and gastric carcinoma. Am J Gastroenterol 93: 1841-1847, 1998.

22. Sugimoto M, Zali MR and Yamaoka Y: The association of vacA genotypes and Helicobacter pylori-related gastroduodenal diseases in the middle east. Eur J Clin Microbiol Infect Dis 28: 1227-1236, 2009.

23. Cover TL and Blanke SR: Helicobacter pylori VacA, a paradigm for toxin multifunctionality. Nat Rev Microbiol 3: 320-332, 2005.

24. Galmiche A, Rassow J, Doye A, Cagnol S, Chambard JC, Contamin S, de Thillot V, Just I, Ricci V, Solcia E, et al: The N-terminal $34 \mathrm{kDa}$ fragment of Helicobacter pylori vacuolating cytotoxin targets mitochondria and induces cytochrome c release. ЕMBO J 19: 6361-6370, 2000.

25. Abdi E, Latifi-Navid S, Latifi-Navid H and Safarnejad B: Helicobacter pylori vacuolating cytotoxin genotypes and preneoplastic lesions or gastric cancer risk: A meta-analysis. J Gastroenterol Hepatol 31: 734-744, 2016.

26. Sipponen P and Price AB: The sydney system for classification of gastritis 20 years ago. J Gastroenterol Hepatol 1 (Suppl 26): 31-34, 2011.

27. Luna LG: Manual of histologic staining methods of the Armed Forces Institute of Pathology. Blakiston Division, McGraw-Hill, New York, NY, 1968.

28. Sambrook J and Green MR: Molecular cloning: A laboratory manuals. Cold Spring Harbor Laboratory Press, Cold Spring Harbor, NY, 2012.

29. Rudi J, Kolb C, Maiwald M, Kuck D, Sieg A, Galle PR and Stremmel W: Diversity of Helicobacter pylori vacA and cagA genes and relationship to VacA and CagA protein expression, cytotoxin production, and associated diseases. J Clin Microbiol 36: 944-948, 1998.

30. Wagih HM,El-Ageery SM and Alghaithy AA: A study of RUNX3, E-cadherin and $\beta$-catenin in CagA-positive Helicobacter pylori associated chronic gastritis in Saudi patients. Eur Rev Med Pharmacol Sci 19: 1416-1429, 2015.

31. Osman EY, El-Eragi AM, Musa AM, El-Magboul SB, A/Rahman MB and Abdo AE: Detection of Helicobacter pylori glmM gene in bovine milk using Nested polymerase chain reaction. Vet World 8: 913-917, 2015.

32. Rhead JL, Letley DP, Mohammadi M, Hussein N, Mohagheghi MA, Eshagh Hosseini M and Atherton JC: A new Helicobacter pylori vacuolating cytotoxin determinant, the intermediate region, is associated with gastric cancer. Gastroenterology 133: 926-936, 2007.

33. Chomczynski P and Sacchi N: Single-step method of RNA isolation by acid guanidinium thiocyanate-phenol-chloroform extraction. Anal Biochem 162: 156-159, 1987.

34. Yilmaz V, Oflazer P, Aysal F, Durmus H, Poulas K, Yentur SP, Gulsen-Parman Y, Tzartos S, Marx A, Tuzun E, et al: Differential Cytokine Changes in Patients with Myasthenia Gravis with Antibodies against AChR and MuSK. PLoS One 10: e0123546, 2015.
35. Moraes-Vieira PM, Takenaka MC, Silva HM, Monteiro SM, Agena F, Lemos F, Saitovitch D, Kalil J and Coelho V: GATA3 and a dominant regulatory gene expression profile discriminate operational tolerance in human transplantation. Clin Immunol 142: 117-126, 2012.

36. Schnopp C, Rad R, Weidinger A, Weidinger S, Ring J, Eberlein B, Ollert $\mathrm{M}$ and Mempel M: Fox-P3-positive regulatory T cells are present in the skin of generalized atopic eczema patients and are not particularly affected by medium-dose UVA 1 therapy. Photodermatol Photoimmunol Photomed 23: 81-85, 2007.

37. Wang L, Qian J, Lu Y, Li H, Bao H, He D, Liu Z, Zheng Y, He J, Li Y, et al: Immune evasion of mantle cell lymphoma: Expression of B7-H1 leads to inhibited T-cell response to and killing of tumor cells. Haematologica 98: 1458-1466, 2013.

38. Bao H, Lu P, Li Y, Wang L, Li H, He D, Yang Y, Zhao Y, Yang L, Wang M, et al: Triggering of toll-like receptor-4 in human multiple myeloma cells promotes proliferation and alters cell responses to immune and chemotherapy drug attack. Cancer Biol Ther 11: 58-67, 2011.

39. Livak KJ and Schmittgen TD: Analysis of relative gene expression data using real-time quantitative PCR and the 2(-Delta Delta C(T)) method. Methods 25: 402-408, 2001.

40. Scheller HV, Jensen JK, Sørensen SO and Harholt J: Biosynthesis of pectin. Physiologia Plantarum 129: 283-295, 2006.

41. Mukaka MM: Statistics Corner: A guide to appropriate use of Correlation coefficient in medical research. Malawi Med J 24: 69-71, 2012.

42. Amieva M and Peek RM Jr: Pathobiology of Helicobacter pylori-induced gastric cancer. Gastroenterology 150: 64-78, 2016.

43. Gonzalez-Valencia G, Atherton JC, Munoz O, Dehesa M, la Garza AM and Torres J: Helicobacter pylori vacA and cagA genotypes in mexican adults and childre. J Infect Dis 182: 1450-1454, 2000.

44. Liu C, Zhang Z and Zhu M: Immune responses mediated by Th17 cells in Helicobacter pylori infection. Integrative Med Int 3: 57-63, 2016.

45. Yu S, Kim HY, Chang YJ, DeKruyff RH and Umetsu DT: Innate lymphoid cells and asthma. J Allergy Clin Immunol 133: 943-950, 2014

46. Brooks C, Pearce N and Douwes J: The hygiene hypothesis in allergy and asthma: An update. Curr Opin Allergy Clin Immunol 13: 70-77, 2013.

47. Kayhan B, Arasli M, Eren H, Aydemir S, Kayhan B, Aktas E and Tekin I: Analysis of peripheral blood lymphocyte phenotypes and Th1/Th2 cytokines profile in the systemic immune responses of Helicobacter pylori infected individuals. Microbiol Immunol 52: 531-538, 2008.

48. Guiney DG, Hasegawa P and Cole SP: Helicobacter pylori preferentially induces interleukin 12 (IL-12) rather than IL-6 or IL-10 in human dendritic cells. Infect Immun 71: 4163-4166, 2003.

49. Hafsi N, Voland P, Schwendy S, Rad R, Reindl W, Gerhard M and Prinz C: Human dendritic cells respond to Helicobacter pylori, promoting NK cell and Th1-effector responses in vitro. J Immunol 173: 1249-1257, 2004.

50. Amedei A, Cappon A, Codolo G, Cabrelle A, Polenghi A, Benagiano M, Tasca E, Azzurri A, D'Elios MM, Del Prete G and de Bernard M: The neutrophil-activating protein of Helicobacter pylori promotes Th1 immune responses. J Clin Invest 116: 1092-1101, 2006.

51. Bagheri N, Razavi A, Pourgheysari B, Azadegan-Dehkordi F, Rahimian G, Pirayesh A, Shafigh M, Rafieian-Kopaei M, Fereidani R, Tahmasbi K and Shirzad H: Up-regulated Th17 cell function is associated with increased peptic ulcer disease in Helicobacter pylori-infection. Infect Genet Evol 60: 117-125, 2018.

52. Bagheri N, Shirzad H, Elahi S, Azadegan-Dehkordi F, Rahimian G, Shafigh M, Rashidii R, Sarafnejad A, Rafieian-Kopaei M, Faridani R, et al: Downregulated regulatory $\mathrm{T}$ cell function is associated with increased peptic ulcer in Helicobacter pylori-infection. Microb Pathog 110: 165-175, 2017.

53. Bagheri N, Shirzad H, Mirzaei Y, Nahid-Samiei M, Sanaei M, Rahimian G, Shafigh M, Zandi F, Tahmasbi K and Razavi A: T-bet cells polarization in patients infected with Helicobacter pylori increase the risk of peptic ulcer development. Arch Med Res 50: 113-121, 2019. 
54. D'Elios MM and Czinn SJ: Immunity, inflammation, and vaccines for Helicobacter pylori. Helicobacter 19 (Suppl 1) 19-26, 2014

55. Downs-Canner S, Berkey S, Delgoffe GM, Edwards RP, Curiel T, Odunsi K, Bartlett DL and Obermajer N: Suppressive IL-17A(+) Foxp3(+) and ex-Th17 IL-17A(neg)Foxp3(+) Treg cells are a source of tumour-associated Treg cells. Nat Commun 8: 14649, 2017.

56. Dianzani C, Minelli R, Gigliotti CL, Occhipinti S, Giovarelli M, Conti L, Boggio E, Shivakumar Y, Baldanzi G, Malacarne V, et al: B7h triggering inhibits the migration of tumor cell lines. J Immunol 192: 4921-4931, 2014.

57. Tan S, Noto JM, Romero-Gallo J, Peek RM Jr and Amieva MR: Helicobacter pylori perturbs iron trafficking in the epithelium to grow on the cell surface. PLoS Pathog 7: e1002050, 2011.

58. Yang XO, Nurieva R, Martinez GJ, Kang HS, Chung Y, Pappu BP, Shah B, Chang SH, Schluns KS, Watowich SS, et al: Molecular antagonism and plasticity of regulatory and inflammatory $\mathrm{T}$ cell programs. Immunity 29: 44-56, 2008
59. Zhuang Y, Shi Y, Liu XF, Zhang JY, Liu T, Fan X, Luo J, Wu C, Yu S, Chen L, et al: Helicobacter pylori-infected macrophages induce Th17 cell differentiation. Immunobiology 216: 200-207, 2011.

60. Das S, Suarez G, Beswick EJ, Sierra JC, Graham DY and Reyes VE: Expression of B7-H1 on gastric epithelial cells: Its potential role in regulating $\mathrm{T}$ cells during Helicobacter pylori infection. J Immunol 176: 3000-3009, 2006.

61. Mitchell P, Germain C, Fiori PL, Khamri W, Foster GR, Ghosh S, Lechler RI, Bamford KB and Lombardi G: Chronic exposure to Helicobacter pylori impairs dendritic cell function and inhibits Th1 development. Infect Immun 75: 810-819, 2007.

(i) $(-)$ This work is licensed under a Creative Commons Attribution-NonCommercial-NoDerivatives 4.0 International (CC BY-NC-ND 4.0) License. 